\title{
norden
}

Nordic Council of Ministers

\section{The Nordic Region - Leading in Green Growth}

Status report for the Nordic Prime Ministers Summer Meeting 2015
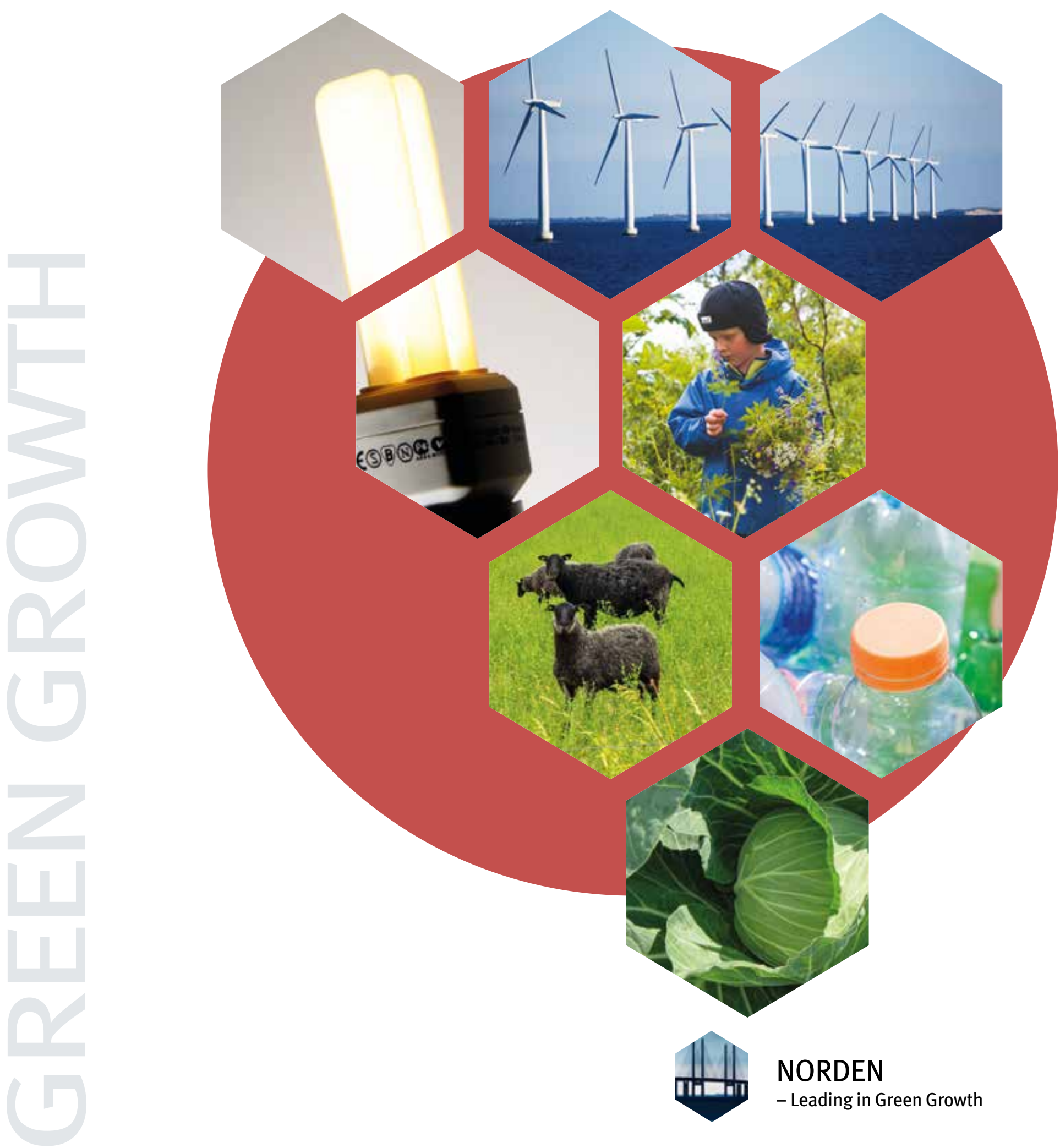
ISBN 978-92-893-4227-8 (PRINT)

ISBN 978-92-893-4228-5 (PDF)

http://dx.doi.org/10.6027/ANP2015-762

ANP 2015:762

(C) Nordic Council of Ministers 2015

Layout: Gitte Wejnold

Photos: Norden.org; Colourbox; ImageSelect

Print: Rosendahls-Schultz Grafisk

Copies: 200

Typeface: Meta LF

Paper: Munken Polar

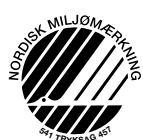

Printed in Denmark

www.norden.org/nordpub

\section{Nordic co-operation}

Nordic co-operation is one of the world's most extensive forms of regional collaboration, involving Denmark, Finland, Iceland, Norway, Sweden, and the Faroe Islands, Greenland, and Åland.

Nordic co-operation has firm traditions in politics, the economy, and culture. It plays an important role in European and international collaboration, and aims at creating a strong Nordic community in a strong Europe.

Nordic co-operation seeks to safeguard Nordic and regional interests and principles in the global community. Common Nordic values help the region solidify its position as one of the world's most innovative and competitive.

\section{Nordic Council of Ministers}

Ved Stranden 18

DK-1061 Copenhagen $\mathrm{K}$

Phone (+45) 33960200 


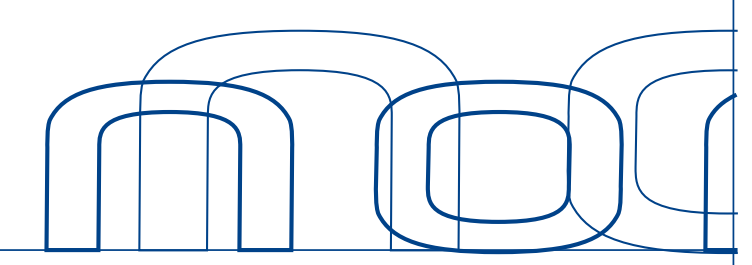

\title{
The Nordic Region - Leading in Green Growth
}

\author{
Status report for the Nordic Prime Ministers Summer Meeting 2015
}

\section{Foreword \\ Green Growth has been one of the priority programmes of the Nordic Council of Ministers since it was launched by the Nordic Prime Ministers in November 2011. The aim was to make the Nordic region a leader in green growth.}

The Prime Ministers' vision for the programme was to identify areas in which the Nordic countries could build on existing positions of strength, improve coordination between the Nordic countries, and lead the way in relation to developments in the European Union (EU). As Secretary General of the Nordic Council of Ministers, it gives me great pleasure to report that the Nordic region has made great advances in all these areas.

The various initiatives span a broad area: education and research, the electricity market, the construction sector, ecodesign and energy efficiency, collaboration on green public procurement, waste management, test centres, development aid, and green investments. All these initiatives are aimed at tackling the major environmental and climate challenges, and helping the Nordic countries improve their market positions.

The Nordic Council of Ministers granted a total of DKK 66 million to the eight focus areas in the period 2012-2015. Most initiatives are expected to be completed by the end of 2015 , but some will continue into 2016. However, we cannot expect to see and reap the benefits of the longer-term results and political effects until later.

We can already see that the results of the programme indicate great potential for improving resource efficiency, reducing emissions of greenhouse gases, and creating new jobs in the Nordic region. Textile collection and re-use alone can create 4000 new jobs. Green growth in practice!

The Green Growth programme has built a solid base from which the Nordic Council of Ministers can continue its work on innovative green solutions. In 2015, the Nordic Council of Ministers will continue to disseminate results from the programme in several international forums, in order to spread our positive Nordic experiences to a broader target group.

I am convinced that the programme has helped us to strengthen Nordic skills, improve coordination between the Nordic countries, and brand us internationally as a region where green growth, innovation and sustainable development is a reality not just a vision for the future.

\section{Dagfinn Høybråten}

Secretary General

Nordic Council of Ministers

\section{The eight focus areas of the Prime Ministers:}

Nordic test centres for green solutions - focus on bioeconomy and biorefineries

2 Education and research that promotes green growth

3 Consumer flexibility on the Nordic electricity market

4 Green technical norms and standards

5 Green procurement in the public sector in the Nordic region

6 Development of technology and methods for processing waste

7 Integration of environment and climate in development aid

8 Funding of green investments and businesses 


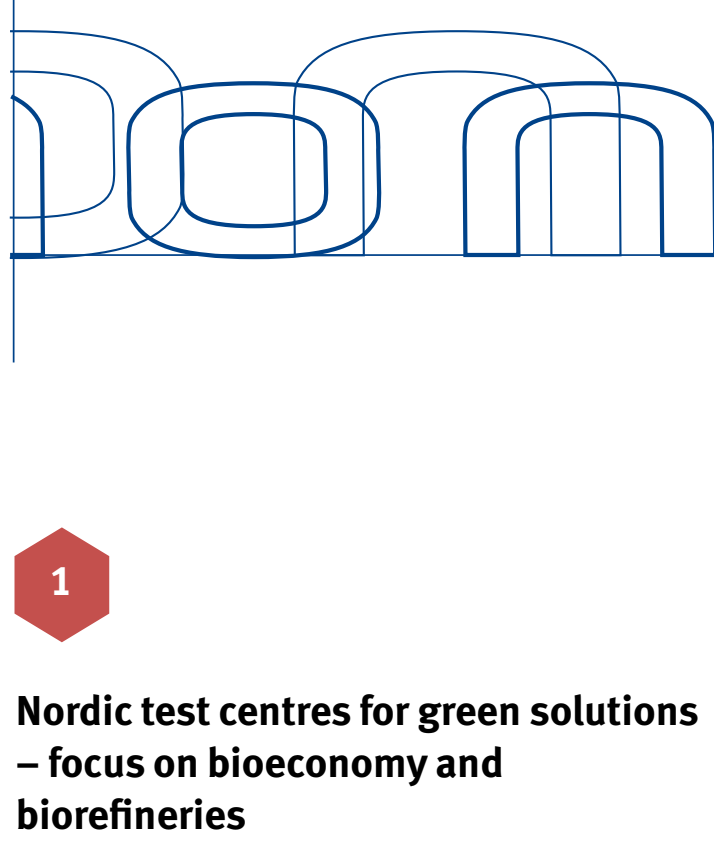

Tasks:

- Examine the opportunities for Nordic collaboration in existing national schemes where energy technology can be tested and developed on a large scale.

- $\quad$ Examine the opportunities afforded by, and added value to be derived from, establishing new, joint Nordic test and demonstration facilities.

\section{Responsibility:}

The Ministers for Energy, in collaboration with the Ministers for Trade, Research, Transport and Agriculture.

The project has resulted in policy recommendations on setting up a Nordic collaboration on biorefineries. The recommendations emphasise, for example, the ability of the bioeconomy to help develop rural districts and coastal areas, and to generate growth in small and medium-sized companies.

In the course of 2015, the recommendations will be considered by the Council of Ministers for Fisheries and Aquaculture, Agriculture, Food and Forestry (MRFJLS) and the Council of Ministers for Trade, Energy and Regional Policies (MR-NER), and this is expected to lead to continued collaboration and follow-up in the area.

The work on test centres began in 2012 with the report, Mapping of Green Energy Test Facilities and Demonstration Sites in the Nordic Countries, which identified 45 existing test and demonstration facilities in the Nordic region. The report showed that there is potential for greater Nordic collaboration in the area, and that there would be advantages in sharing the high investment and operating costs.

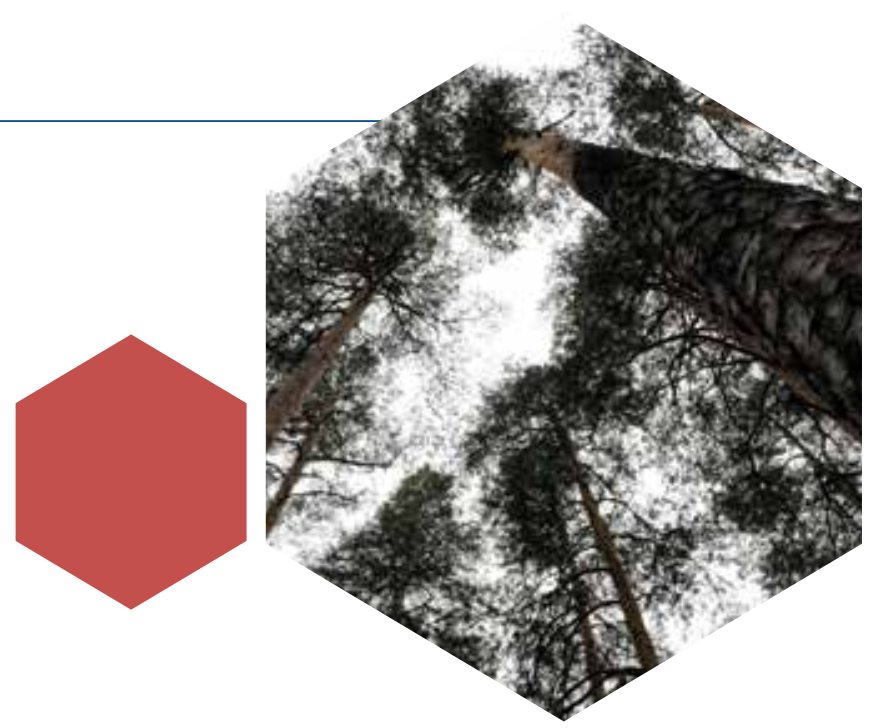

On the basis of the survey, the Council of Ministers for Fisheries and Aquaculture, Agriculture, Food and Forestry, in collaboration with the Council of Ministers for Trade, decided to look further into Nordic collaboration on biorefineries, in order to optimise utilisation of biological resources that are either under-used or not used at all today.

Several biorefinery facilities for upgrading side- and waste-product flows from primary industries are already in place, but development is currently slow and the products usually limited to low-value areas like energy and fertiliser. Already known technologies offer the possibility of upgrading organic resources to the entire value range of products, from health, through food and food ingredients, chemicals and functional materials, to energy and soil improvement.

The recommendations include making bioeconomy a joint top priority in the Nordic region to enable faster implementation. The countries will join forces on research and development regarding technologies and facilities for upgrading organic waste and residual products from primary industries to both high-value products and energy.

The countries are also encouraged to develop incentive structures to create a market for new biorefinery products and influence EU regulations, which inadvertently discourage improvement of resource efficiency in the bioeconomy and the potential in the circular economy.

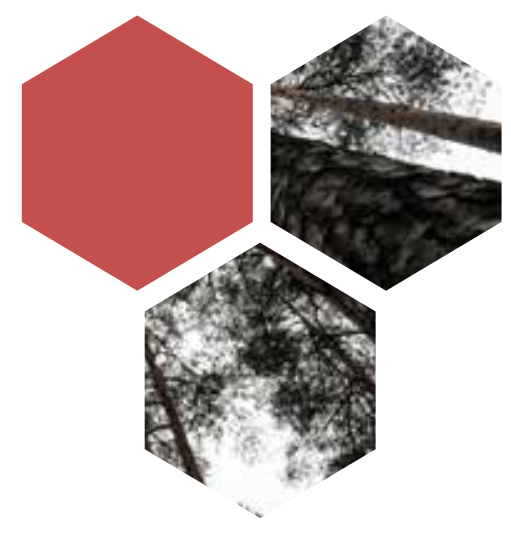




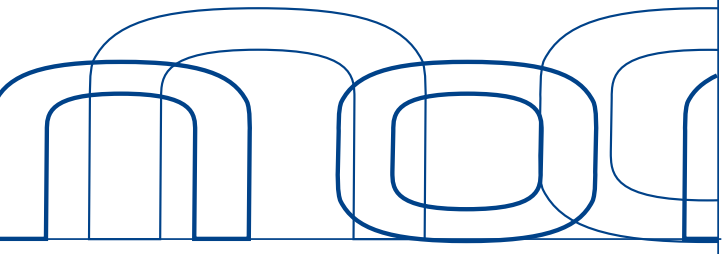

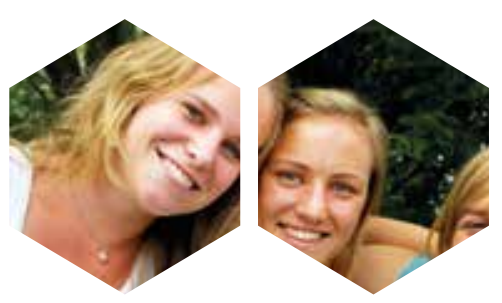

\section{Education and research that promotes green growth}

Tasks:

- Develop Nordic collaboration in education and research that promotes green growth.

\section{Responsibility:}

The Ministers for Education and Research, in collaboration with the Ministers for Energy and Trade.

Six different projects have been set up in the focus area of education and research. The projects span the entire education spectrum, from children and young people to adults, and have a common objective to strengthen sustainable development and green growth. The projects have now spread to a large number of educational institutions in the Nordic region. The largest single initiative is a joint Nordic research project, with an expected total budget of NOK 80 million.

\section{Green Growth - Understanding Societal Challenges} The five Nordic countries are now joining forces to develop a major interdisciplinary research and innovation programme about green growth, with the working title Green Growth - Understanding Societal Challenges. The programme brings together leading Nordic researchers in climate, environment and energy with the business community and innovation environments, with the aim of implementing theories and ambitions regarding green growth in practice in Nordic business and working life.

The programme will focus on research and innovation fields concerned with green growth where the Nordic region has common interests and can contribute solutions internationally. Synergies will be generated in relation to other relevant initiatives in the Nordic region and internationally, such as the Nordic programme for Arctic research, the planned Nordic collaboration on bioeconomy, and the Top-level
Research Initiative (TRI), which has generated good results in climate and environmental research.

One important priority is to highlight the social conditions associated with green growth and policy implications of this knowledge. The programme will promote broad use of the results in education, research, business, and administration. The overall budget is approximately NOK 80 million, which apart from green growth funds, is also financed by NordForsk, Nordic Innovation and Nordic Energy Research, and research and innovation institutions in all the Nordic countries.

\section{Great Nordic Climate Duel and learning portal} The Nordic Climate Day 2014 was the launch pad for the Great Nordic Climate Duel, a competition about saving energy for pupils between the ages of 12 and 16 in the Nordic region. The 'duel' combines teaching materials, themes and competitions on energy, climate and environment.

The aim is to offer Nordic teaching materials that promote collaboration between pupils, and make them more aware of their responsibility and what they can do to help resolve climate and environmental challenges. The content is available in five languages, and is fully integrated on the learning portal, Norden i Skolen (the Nordic Region in the School) under the Federation of the Norden Associations. Sixty-one schools have registered, and the competition website has received 11,000 unique visitors. The themes for Climate Duel 2015 are food waste, sustainable purchasing habits, and methods for waste processing, inspired by the Nordic green growth projects.

The learning portal www.nordeniskolen.org is an educational resource for Nordic teachers who work with the subjects Language \& Culture and Climate \& Nature. The portal has 3800 registered users, across 2000 schools with a total of 40,000 pupils. The vision of the themes of Climate \& Nature is to incorporate the natural and social sciences into a Nordic context, ensure a solid scientific foundation in climate, 


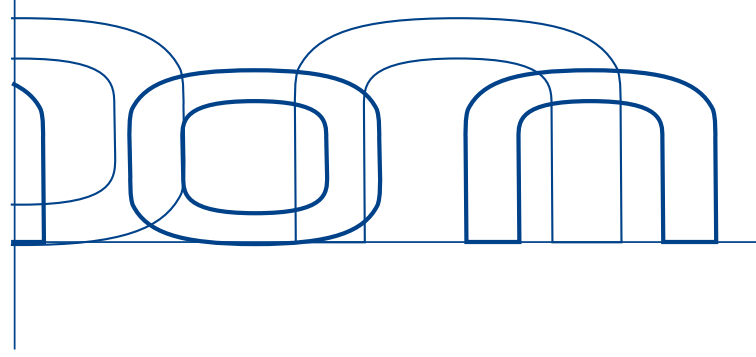

sustainability and green solutions, and support the students' innovative skills.

In 2015 the Climate Duel will be translated to English, Greenlandic, Faroese and Sami, and will be further developed as an app for mobile phones and tablets. This will make the concept more accessible to children and young people in the Arctic region and internationally.

\section{Biophilia}

The Biophilia educational programme was set up as a Nordic collaboration project during the Icelandic presidency in 2014. The programme explores the interplay between science, creativity, technology and music, and the aim is to support the learning and innovative skills of children and young people through interdisciplinary and creative learning methods.

Nordic researchers, scientists, artists and teachers, in collaboration with the Icelandic artist Björk, developed teaching ideas for the project. The teaching material is available at www. biophiliaeducational.org, which also serves as a forum for sharing ideas and experiences.

The programme is also a collaboration platform for researchers in the Nordic region, who will stimulate young people's interest in research and education through a Nordic tour with lectures, courses and interactive teaching. Nordic knowledge disseminators, introduced to the project in 2014, also produced guidelines, and film and teaching materials for the tour.

\section{PILOT - Knowledge for sustainable development - Nordic adult education}

Nordic adult education organisations have launched a pilot educational programme in sustainable development. The objective is to increase knowledge about sustainability and to explore how it can be promoted, both locally and globally. Nineteen students from all over the Nordic region have participated at four meetings, in Norway, Denmark, Sweden and Finland. The participants present their projects, which are linked to the local environment they represent. The work takes place in cross-Nordic groups, where participants share their experiences in order to use and disseminate Nordic strengths in the work to attain a sustainable and just world.

The methods and educational ideas of the pilot programme have so far been presented at seven international conferences and seminars and in several publications. The project will be evaluated in 2015, to determine whether the educational programme can be offered at a larger scale and as a permanent educational programme for adult education providers in the Nordic region.

\section{Implementation of Rio+20 in Nordic universities and higher education institutions}

The project has carried out a major survey of how sustainable development measures are implemented in Nordic universities and higher education institutions. The aim was to increase collaboration between institutions and to engage decisionmakers in implementing the Rio+20 sustainability goals relating to the operation of, and educational programmes offered by, educational institutions. The results are presented in 2015 in a report that provides an overview of the level of sustainability in Nordic educational institutions, and describes the steering mechanisms, drivers and barriers that influence the implementation.

\section{Nordic Master in Green Growth}

The Nordic Master in Green Growth is a two-year Master's educational programme of 120 ECTS points, which will be set up in collaboration between at least three universities in the Nordic countries, and the Faroe Islands, Greenland and Åland. Teaching will be in English, to attract Nordic, European and international students. The Nordic Master's programme will be introduced in June-September 2015 , and the consortium behind the programme will be put together in October. Students will be admitted to the programme in 2016 and 2017.

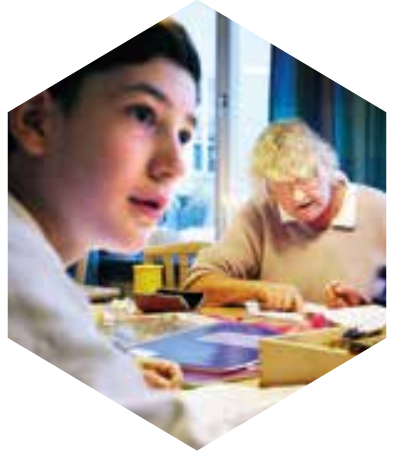




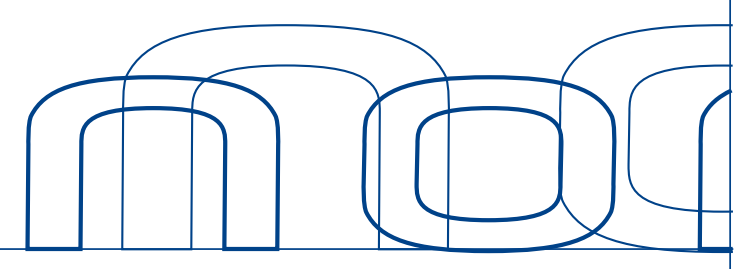

\section{Consumer flexibility on the Nordic electricity market}

Tasks:

- Increase the focus on the demand side in the electricity market collaboration in the Nordic region, including promoting flexible consumption of electricity, sharing experiences at Nordic level, and coordinating the development and implementation of smart networks and electricity meters.

- $\quad$ Promote partnerships with leading players in the industry and the service sector in order to share experiences and best practice in relation to consumer flexibility and energy efficiency.

\section{Responsibility:}

The Ministers for Energy, in collaboration with the Ministers for Trade.

The report Demand Response in the Nordic Electricity Market was issued in 2014, with two main conclusions. Firstly, greater understanding is needed of future demand in the electricity market before measures to promote flexibility can be efficiently implemented. Secondly, an overall strategy is needed to ensure optimal utilisation of the flexibility, regardless of whether this comes from consumption, production, storage or reinforcement of the network.

Before consumer flexibility can be considered an effective instrument to balance supply and demand on the electricity market, new technology must be developed. The report recommends that the Nordic countries look more closely at the potential for developing technologies whereby consumers can react to price signals.

The report also concludes that consumer flexibility is best secured through effective and transparent markets. There are two crucial conditions for increased flexibility: firstly, consumers must be able to monitor their consumption in real-time and,

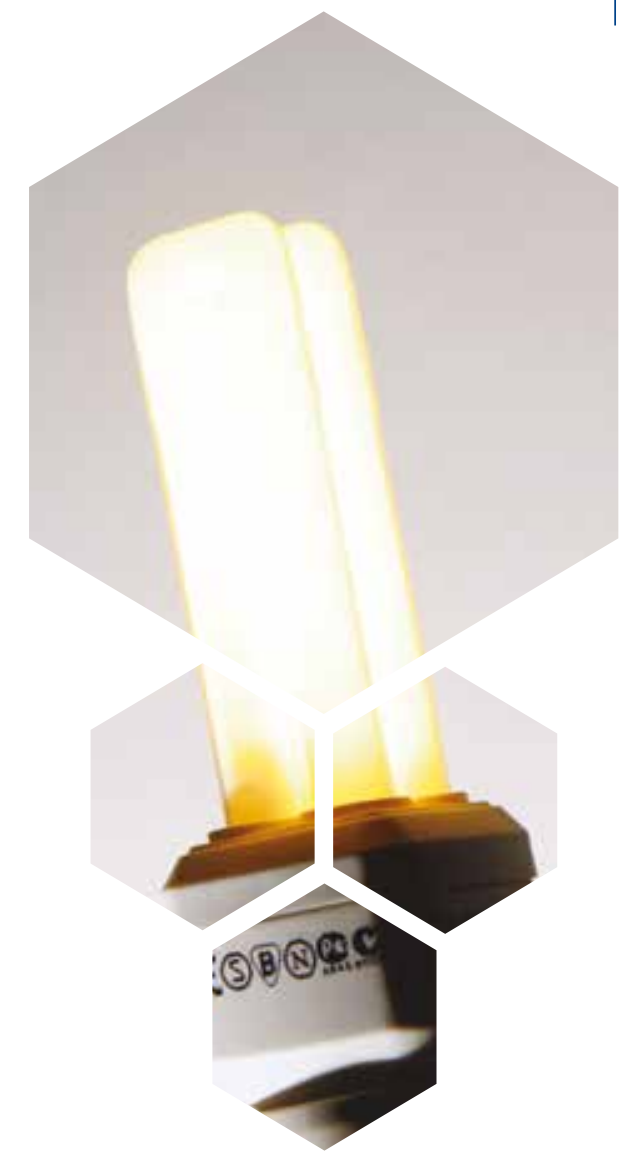

secondly, they must have a clear price incentive to adjust their consumption in accordance with prevailing electricity prices. It is important to understand that consumer flexibility is not a goal in itself, but rather a means to improve balance in the market.

The project is completed, but the Nordic Council of Ministers Electricity Market Group is continuing the work on consumer flexibility in the electricity market. The Electricity Market Group has commissioned NordREG, the Nordic electricity regulator, for input on whether the conclusions in the report can be taken further.

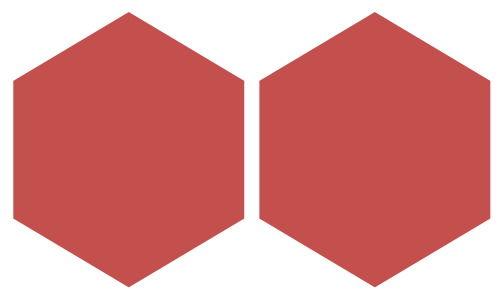




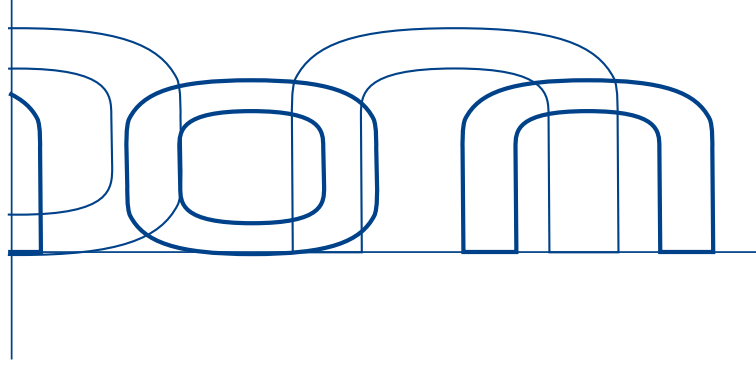

4

\section{Green technical norms and standards}

\section{Tasks:}

- Identify 4-5 key areas in construction where technical norms and standards could be suitable for Nordic co-ordination, and develop proposals for how the barriers in these areas can be removed.

- Through Nordic collaboration, raise the level of ambition of EU work on ecodesign and requirements for energy labelling on many product types.

- Ensure that activities in the existing work plans are implemented.

- Work to ensure that future work plans on energyrelated and energy-using products concern product requirements

\section{Responsibility:}

The Ministers for Energy, in collaboration with the Ministers for Trade and Environment.

Three main projects have been started within this focus area. The projects focus on building standards, 'the Swan' ecolabelling for building renovations, and market surveillance of ecodesign and energy labelling.

The objective of several of the projects is to influence international processes and, in spring 2015, Nordic proposals for common European standards have been placed on the agenda at CEN, the European standards organisation. At Nordic level, work is continuing on developing the Swan ecolabelling for renovations, and this is expected to be completed in 2016.

The initiative has also led to significant advances in Nordic collaboration on market surveillance of ecodesign and energy labelling.

\section{The Nordic region as a standard maker}

The Nordic region as a standard maker comprises three projects that will affect the regulatory framework for the European construction industry in the future. The objective has been to create new

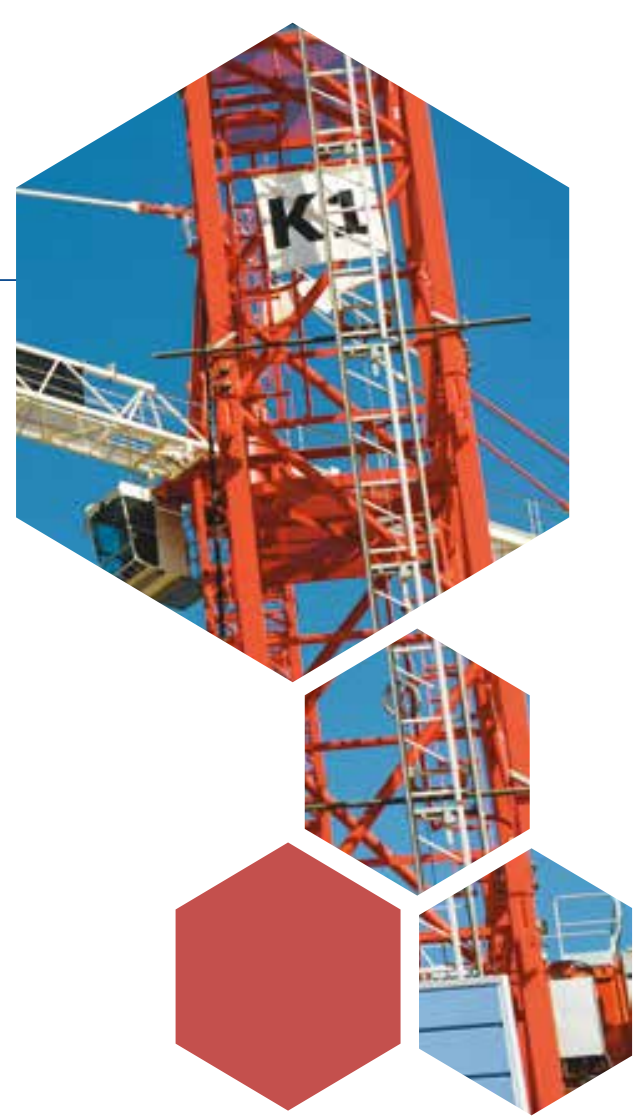

European standards on the basis of Nordic traditions and regulations in three areas: product and building declarations, building renovations, and indoor climate.

The aim of the project Future EU regulation on product and building declarations is to influence implementation of the EU building regulations and increase focus on sustainability and re-use of building materials. The ambition is to ensure that the EU attitude to life-cycle analysis is an extension of the successful methods already in use in Nordic industry. The project has developed product life-cycle analyses for insulation material and steel products that meet the policy requirements for recycling in the EU and comply with the European standard. The clarification will mean that Nordic businesses will be at the forefront of product requirements, and can retain their production and documentation methods.

Sustainable renovation of existing buildings resulted in a Nordic proposal for a new European standard for classifying buildings with regard to renovation. The proposal is based on Nordic expertise in building renovation and the possibility to export Nordic architect and engineering services.

\section{The Indoor climate and voluntary classification} standards project has made a similar proposal for a European standard on indoor climate. The aim is to ensure greater emphasis on indoor climate in energy renovation of existing buildings, based on Nordic traditions regarding air, light and sound. 


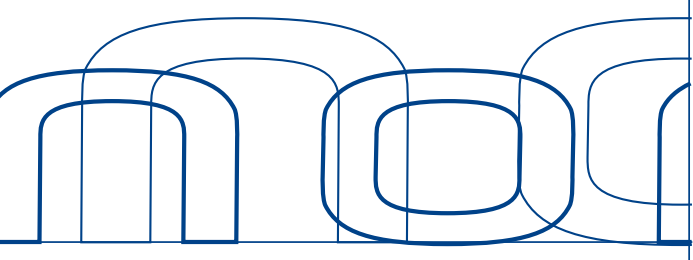

The Nordic proposal for common European standards has been placed on the agenda at CEN, the European standards organisation, in spring 2015. In addition, a targeted public affairs initiative is planned for relevant organisations and EU institutions in June 2015.

\section{The Swan ecolabelling for building renovations}

The objective has been to develop criteria for the Swan ecolabelling for building renovations. These will be described in a criteria document for the Swan ecolabelling for renovation and an associated background report. The Swan ecolabel is for use by private and public contractors who carry out sustainable renovation.

The criteria for the Swan ecolabel will be adapted to all the Nordic countries, and will be based on an overall evaluation of the environmental status of the building. The standard will set stringent but attainable requirements, so that players in the construction sector can use the Swan ecolabel as documentation of their contribution to sustainable development of the building.

The standard will extend the areas of strength of the Swan ecolabel in relation to buildings, including limiting the use of hazardous chemicals, good indoor climate, low energy needs, reduced $\mathrm{CO}_{2}$ emission, and control of the building process. The work is also based on the results from the Sustainable renovation of

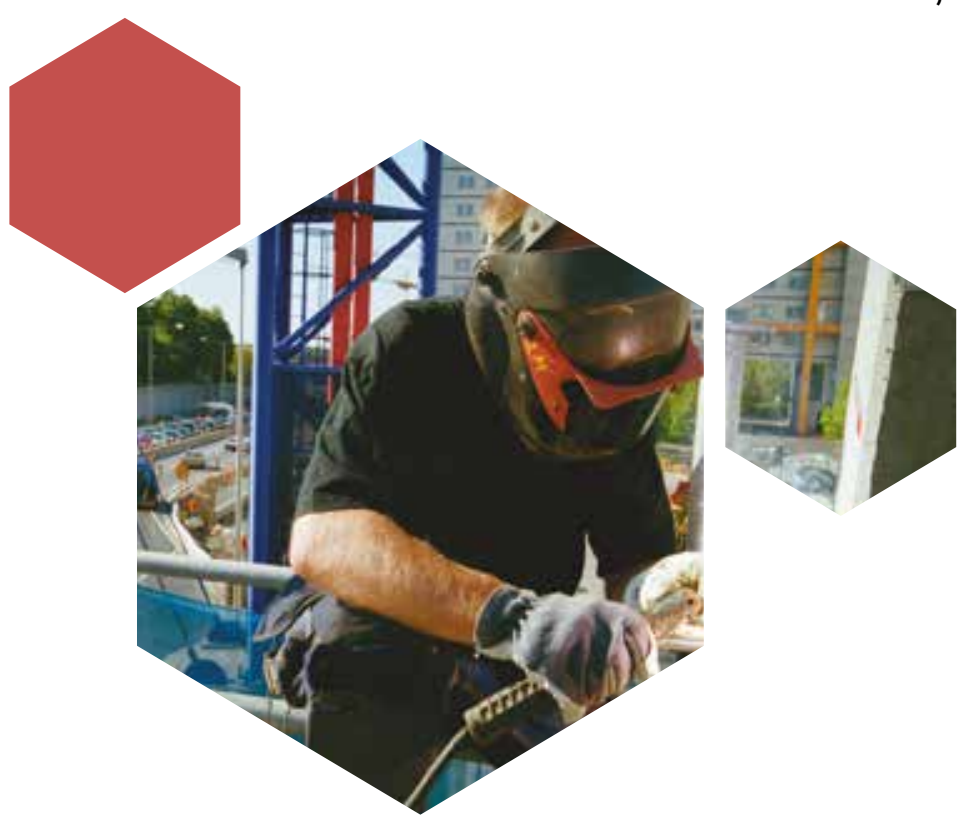

existing buildings project and a market survey carried out by the consulting company, Sweco.

A draft of the requirements standard for the Swan ecolabelling for renovation will be prepared in 2015 and circulated for comments. The standard will be completed in 2016 on the basis of test results and feedback from Nordic contractors and expert groups, after which it will be considered for approval by Nordic Ecolabelling.

\section{Nordsyn}

The aim of Nordsyn is to improve market surveillance of ecodesign and energy labelling in the Nordic region. The project is directed primarily towards the Nordic market surveillance authorities, corresponding European authorities, and producers of energyrelated products.

Nordsyn has made a significant contribution to the Nordic collaboration on market surveillance of ecodesign and energy labelling through coordination, increased dialogue on the interpretation of legislation, collaboration on test and information activities, and sharing of test results and market surveillance plans.

Nordsyn has initiated a number of in-depth studies of the subject, including Effects of Market Control, Strategic Nordic Products, and Survey SME, and a number of guidelines about market surveillance and technical documentation.

In 2015 Nordsyn is focusing on three initiatives: Continual working methods, How to overcome barriers to collaboration and the project Challenges for market control (market control of products that are difficult to monitor). The project will be completed in 2015 with a concluding conference and final report, while the collaboration between the Nordic market surveillance authorities will continue.

Nordsyn's most important results will be presented at the ECEEE Summer Study on Energy Efficiency in June, and at the ADCO meeting in the autumn, which will be attended by the European market surveillance authorities. 


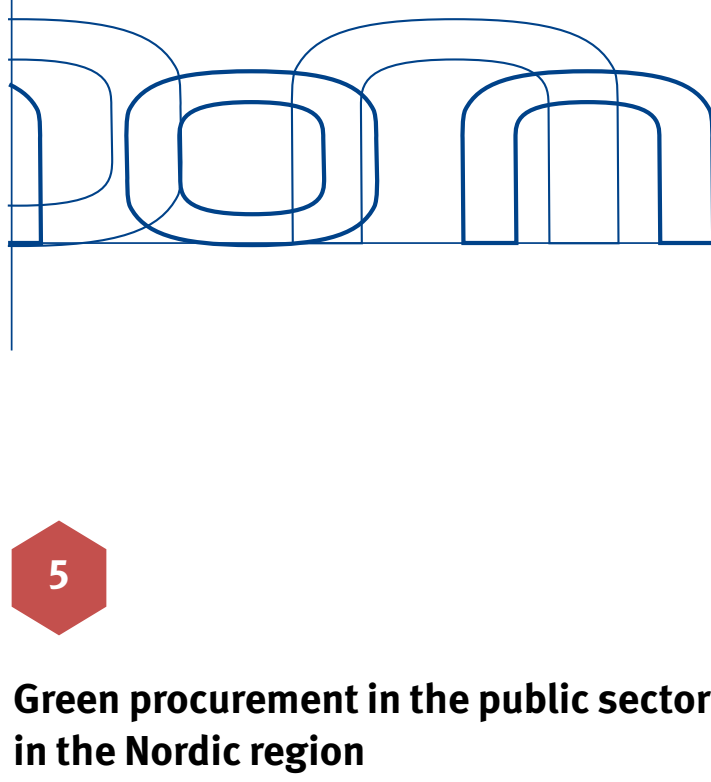

Tasks:

- Initiate a project aimed at, in a first stage, identifying areas and product groups with the most effective green procurement standards compared with other instruments.

- In a second stage, examine how green procurement standards can be coordinated at Nordic level.

- Where green business models can usefully supplement labelling schemes, these can be included in the work.

\section{Responsibility:}

The Ministers for Trade, in collaboration with the Ministers for the Environment and Energy.

The work has involved identifying the most relevant products and services in relation to Green Public Procurement (GPP) and investigating the possibility of developing common Nordic standards in the area. The analysis shows that specific Nordic criteria would not bring noticeable advantages. Instead, the work is now focusing on formulating proposals for joint Nordic initiatives to strengthen a combined Nordic market and develop environmentally sound products and services.

In 2012-2013, the trade and environment sectors conducted a pilot study on GPP and the potential for greater Nordic collaboration in this area. However, the recommendations that were subsequently proposed were not regarded as being sufficiently in line with the Prime Ministers' commission. The Nordic Council of Ministers and Nordic Innovation were commissioned to develop a project more appropriate to the Prime Ministers' intentions.

The report Status on GPP in the Nordic countries was produced in 2015. The report identified the most relevant products and services relating to GPP, and investigated the possibility of developing common Nordic standards in the area. The analysis shows that the product categories had already been identified by national and international authorities, so the EU GPP criteria formed the basis of the criteria used in the Nordic countries. The Nordic players already collaborate, so the conclusion is that the Nordic region would not benefit greatly from setting up common criteria.

However, the strength of a common Nordic market was emphasised, as it would increase purchasing power and enable more specific requirements to apply for the products. The total Nordic budget for public procurement is more than EUR 66 billion per year, so innovative public procurement to a combined Nordic market offers great potential for promoting the development of environmentally sound products and services.

According to the report, management is crucial for successful implementation of green criteria for public procurement. Decision-makers are encouraged to contribute politically and financially to developing efficient procurement structures and well-defined GPP initiatives, and provide qualified training and skills development. The need for better monitoring systems is also emphasised, in order to evaluate the economic and environmental effects of GPP.

Nordic Innovation is organising, partly on the basis of the above report, a workshop in the first six months of 2015. The workshop will gather the players involved in an attempt to identify common Nordic focus areas and projects that can form the basis for future work. 


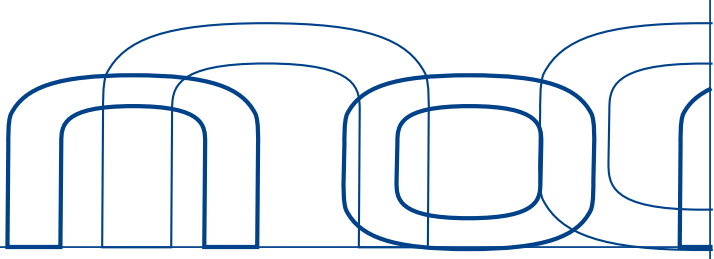

6

\section{Development of technology and methods for processing waste}

Task:

- Develop joint Nordic methods and techniques to select different types of waste, such as building and construction waste, food waste and scrap waste from iron and metal, where there is a potential for creating resource-effective recycling of waste.

\section{Responsibility:}

The Ministers for the Environment and the Ministers for Fisheries and Aquaculture, Agriculture, Food and Forestry, in collaboration with the Ministers for Energy and Trade.

Several projects have been launched to improve the processing of plastic and textile waste, and to reduce food waste in the Nordic region. The projects have mapped current shortcomings, proposed models for future solutions, and formulated guidelines and policy recommendations for Nordic collaboration.

The results show, for example, that increased recycling of waste will considerably improve resource efficiency in the Nordic region, reduce emissions of greenhouse gases, and generate new jobs in the region. The results are expected to make a significant contribution to Nordic collaboration in the coming years, and have also aroused great international interest.

\section{Resource-efficient recycling of plastic and textile waste}

On behalf of the Ministers for the Environment, the Nordic Waste Group launched the initiative called Resource efficient recycling of plastic and textile waste to meet the Prime Ministers' ambition for efficient and sustainable use of waste resources. The initiative comprises three projects on recycling of plastic waste, focusing on plastic packaging from household waste, plastic waste at recycling centres, and plastic from electronic waste. In the textile area, three

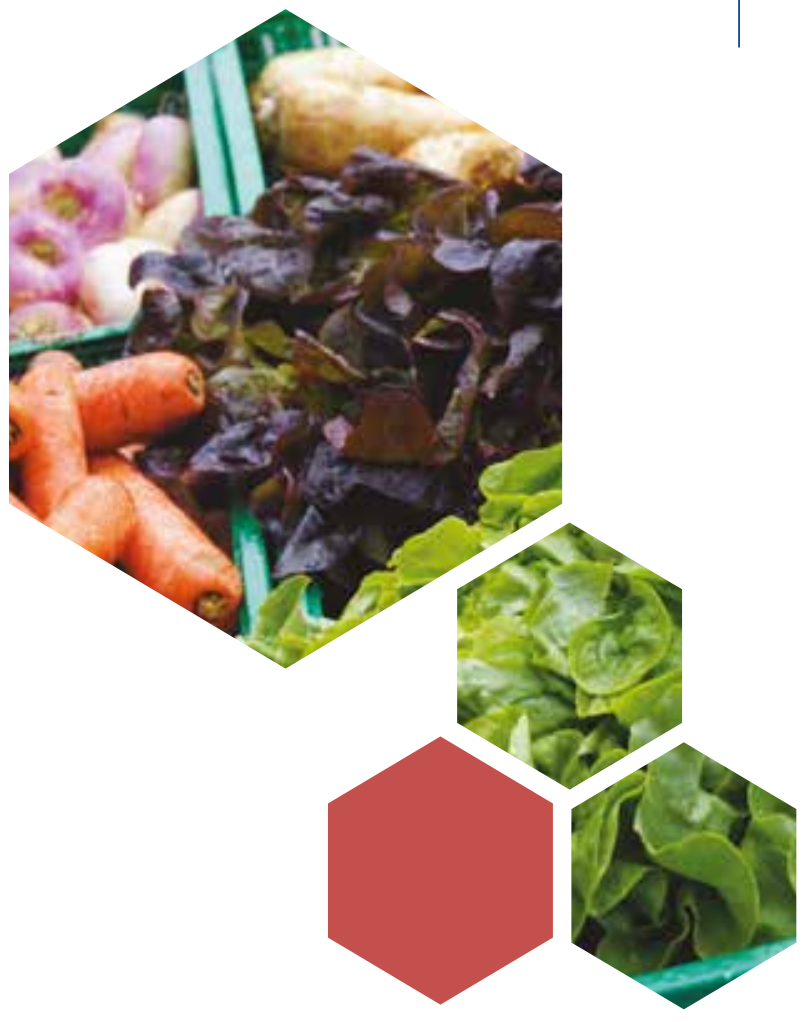

projects have worked to increase collection, sorting, re-use and recycling of textiles in the region.

The results from the projects show that collection and recycling of plastic and textile waste in the Nordic region can be greatly increased. From municipal waste streams alone, the countries can potentially collect and recycle a further 700,000 tons of plastic. A considerable quantity of plastic delivered to recycling centres, and plastic from electronic waste, could also be used much more than is currently the case. Increased recycling of waste will considerably improve resource efficiency in the Nordic region, reduce emissions of greenhouse gases, and generate new jobs in the region.

The projects have proposed tangible strategies and tools to show how private and public players in the plastic value chain can help to increase collection and recycling of plastic. Two of the projects have also developed policy recommendations for Nordic decision-makers, aimed at increasing material recycling of plastic waste.

In the textile area, the results show that increased collection, sorting, re-use and recycling of textiles can reduce the environmental impact of textile use in the Nordic region, boost the competitiveness of the region, and generate green jobs. Annual consumption 


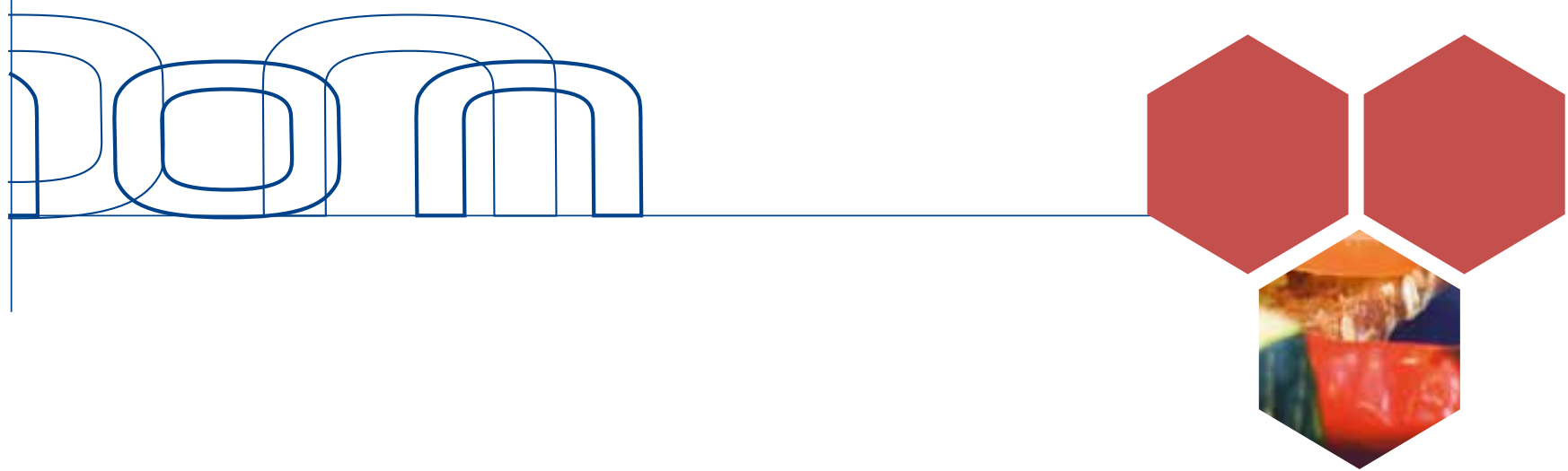

of new textiles in the Nordic countries is 350,000 tons, but only 120,000 tons of used textiles are collected each year. The environmental potential is great, as production of a single $\mathrm{kg}$ of textiles generates $15 \mathrm{~kg}$ of $\mathrm{CO}_{2}$ emissions.

Nordic experts have published three core documents that form the basis for doubling the amounts of textiles collected, re-used and recycled in the Nordic region. The objective is that textiles will be re-used as often as possible during the course of their functional lifetime, and then be recycled. This type of restructuring could potentially lead to over 4000 new jobs in the region.

The work on both plastic and textile waste will continue in 2015 and 2016. The Danish presidency of the Council of Ministers for the Environment in 2015 has launched an action plan for a sustainable textile and fashion sector, which builds on the results from the green growth projects on textile waste.

The results from the plastic and textile projects will also be presented in European and international forums, with the aim of inspiring more environmentally sound consumption, production and processing of plastic and textiles.

\section{Food waste}

In 2012, the food ministers initiated three projects to reduce food waste in the Nordic countries. The projects investigated whether food waste in primary production could be reduced, and whether date labelling and distribution of food to people in need could help to limit food waste in the Nordic region.

Like the rest of the world, there is great potential for reducing food waste in the Nordic countries. The objective of the projects has been to generate knowledge about food waste in primary production and how it can be prevented, help producers to datelabel food in a way that minimises food waste, and promote safe and effective distribution of surplus food to people in need.

The results show that legislation on date labelling of foods is interpreted differently in the Nordic region, for example, assessment of shelf life and
'Use by' stamp. The work will result in common Nordic positions on the use of date labelling to avoid food waste. The results also indicate that more efficient redistribution of food can help to reduce food waste in the Nordic region. The redistribution is mainly direct from donor to recipient, which indicates that food banks could play a greater role.

A survey of food waste in the primary sectors is under way. Six thousand questionnaires have been sent out to producers in the agriculture and aquaculture sectors to obtain an overview of the extent of and reasons for food waste in production. A report will be presented at the start of 2016.

By continuing the Nordic collaboration on food waste, it is expected that the region can take a leading role and present a strong common vision in the EU on developing a green economy. The results of the projects are already part of the European collaboration, and the project group has presented Nordic experiences, models and tools to avoid food waste, with emphasis on primary production, date labelling and redistribution of food. The results have aroused great interest in the EU Expert Group on Food Losses and Food Waste.

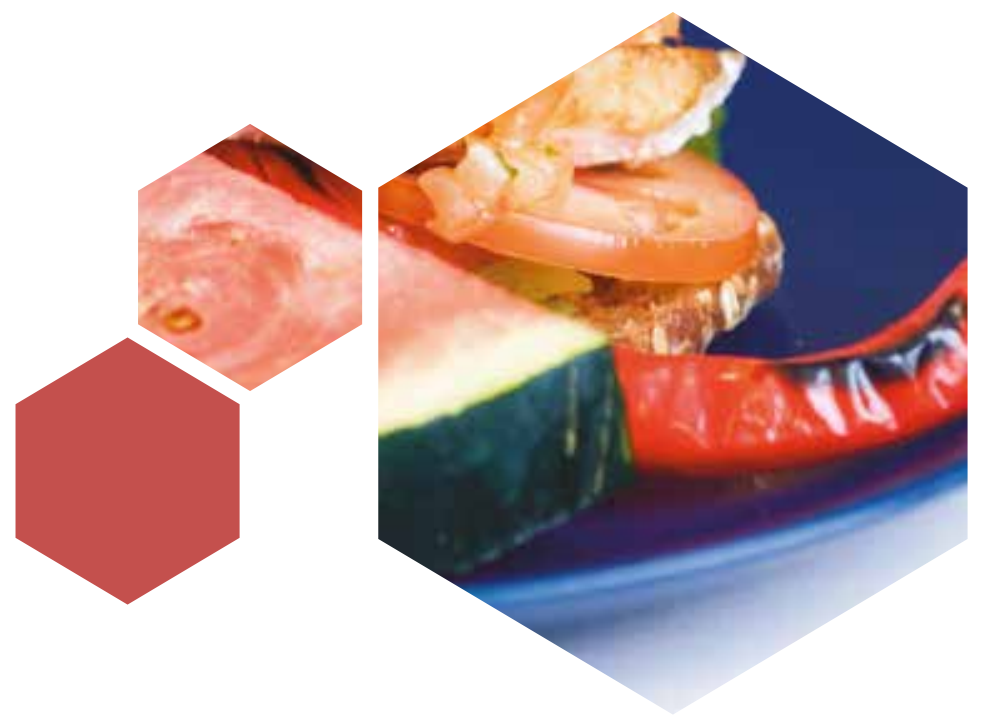




\section{Integration of environment and climate in development aid}

\section{Task:}

- Promote co-ordination in Nordic development aid and strengthen its green focus.

\section{Responsibility:}

Ministers for Development Aid and Ministers for the Environment.

The project shows how low-income countries can phase out ineffective and environmentally hazardous public subsidies to fossil fuels. Research results indicate that a reform of these subsidies can reduce global $\mathrm{CO}_{2}$ emissions considerably, by between 6 and $13 \%$ by 2050 . The project has provided a number of tangible and operational results, each of which plays an important role in the work of phasing out Government-supported fossil fuels, and which are already being used in connection with national subsidy reforms and international climate negotiations.

The project has, for example, developed a calculation model that makes it possible to calculate how much developing countries can reduce their emissions by phasing out state support for fossil fuels. It also presents scenarios for how savings from the subsidy reform could be invested in better energy efficiency and renewable energy. In this way, the Nordic initiative is supporting conversion to a green economy in developing countries.

In 2014, the project presented a report that describes the possibilities for closer Nordic collaboration on restructuring subsidies for fossil fuels. The report considers the social costs connected with retaining the subsidies, and analyses the possibilities for developing social welfare systems by phasing out the support. Furthermore, a 'How to - guidebook' has been published that operationalises the above data and knowledge, and helps the countries to take into account the individual country's budgeted reductions

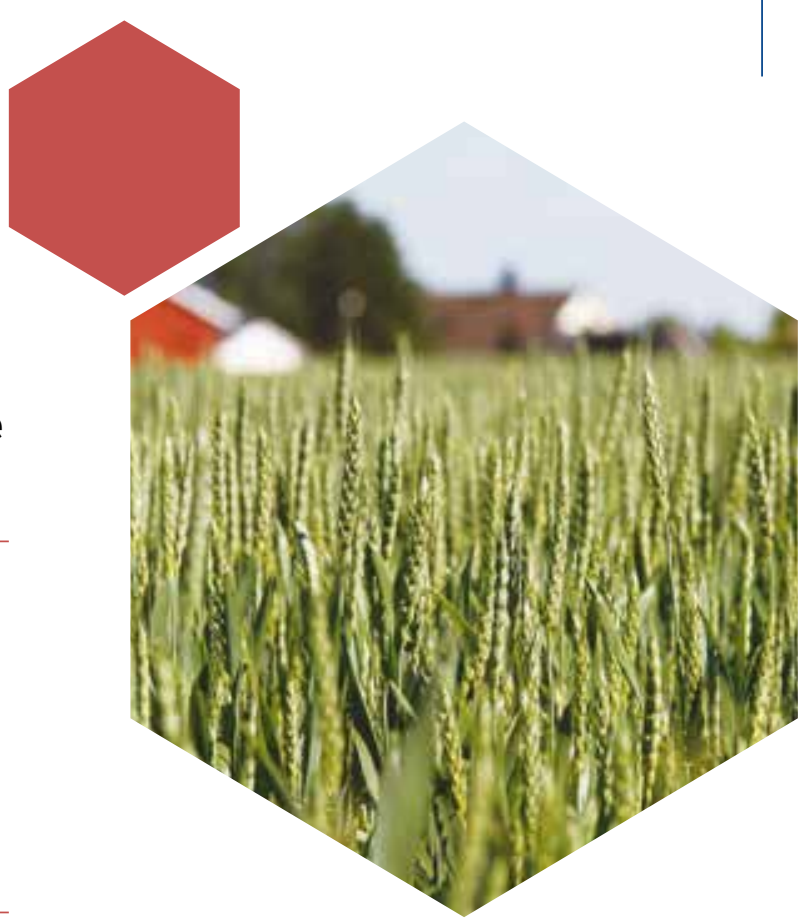

in $\mathrm{CO}_{2}$ emissions by reforming state support for fossil fuels.

The data and information is particularly valuable for those countries looking to reduce their emissions as a part of climate change negotiations. Two developing countries are already using the calculation model produced in the project when reporting reduction potentials to UNFCCC.

The results from the initiative have already been disseminated and have been used in connection with a number of international climate negotiations, including COP 20 in Lima and the UNFCCC climate conferences in 2014 and 2015. The report has already been downloaded from norden.org over 1200 times since it was published in February 2015.

In the course of 2015, the project will be presented in all the most important international forums dealing with subsidies for fossil fuels, including UNFCCC and negotiations on the UN Post-2015 Development Agenda. The final report from the project will be presented in June 2015.

The project is a collaboration between Denmark, Finland, Norway and Sweden, the Nordic Environment Finance Cooperation (NEFCO), International Institute for Sustainable Development and two partner countries. It was launched in the extension of the Nordic involvement in the Friends of Fossil Fuel Subsidy Reform Group. 


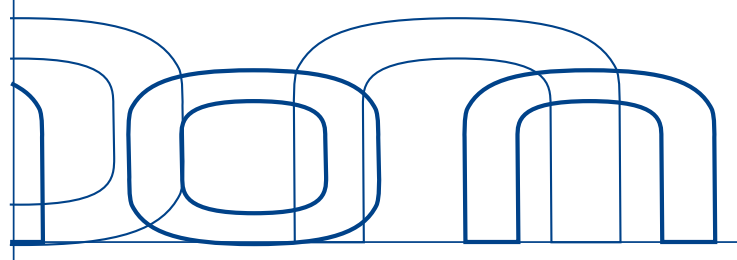

8

\section{Funding of green investments and businesses}

Task:

- $\quad$ Present proposals for how the Nordic Ministers for Finance, Trade and Energy can coordinate and intensify their activities in financial institutions where the Nordic countries as key players can support and stimulate the funding of green businesses and investments.

\section{Responsibility:}

The Ministers for Finance, in collaboration with the Ministers for Trade and Energy.

Three reports have been produced in connection with the initiative. The results show that the potential effects of greater Nordic efforts in the financial institutions are marginal compared with general economic policy instruments, which can influence the entire economy. Despite a clear environmental focus, NIB and NEFCO hold a relatively small market share.

In 2012, the finance ministers initiated an introductory survey to highlight how the Nordic countries could coordinate and increase their work in the Nordic financial institutions to promote funding of green businesses and investment in green growth.

The conclusion was that the institutions in which the Nordic countries have a significant ownership, i.e. the Nordic Investment Bank (NIB) and the Nordic Environment Finance Corporation (NEFCO), are already highly involved in funding green investments and environmental initiatives. However, the analysis also shows that their modest market share limits their influence in relation to the total investment need.

In 2013, the financial collaboration decided to broaden the analysis, working with the environmental sector to also include the countries' use of marketbased instruments that can promote green investments. The analysis compared the countries' ideas on how they can better correct market failures by applying economic policy instruments, such as by compensating for low prices on $\mathrm{CO}_{2}$ emissions.

The initiative came to end in 2015 with a concluding report that describes the Nordic countries' most important prioritisations to promote green investments and improve the environment. The overall results show that there is further potential for green investments in the Nordic region, especially in investment-heavy areas like energy and transport and material and waste management. The report also stated that the countries should continue to be aware of whether their economic policy prioritisations generate the correct incentive for green investments. 


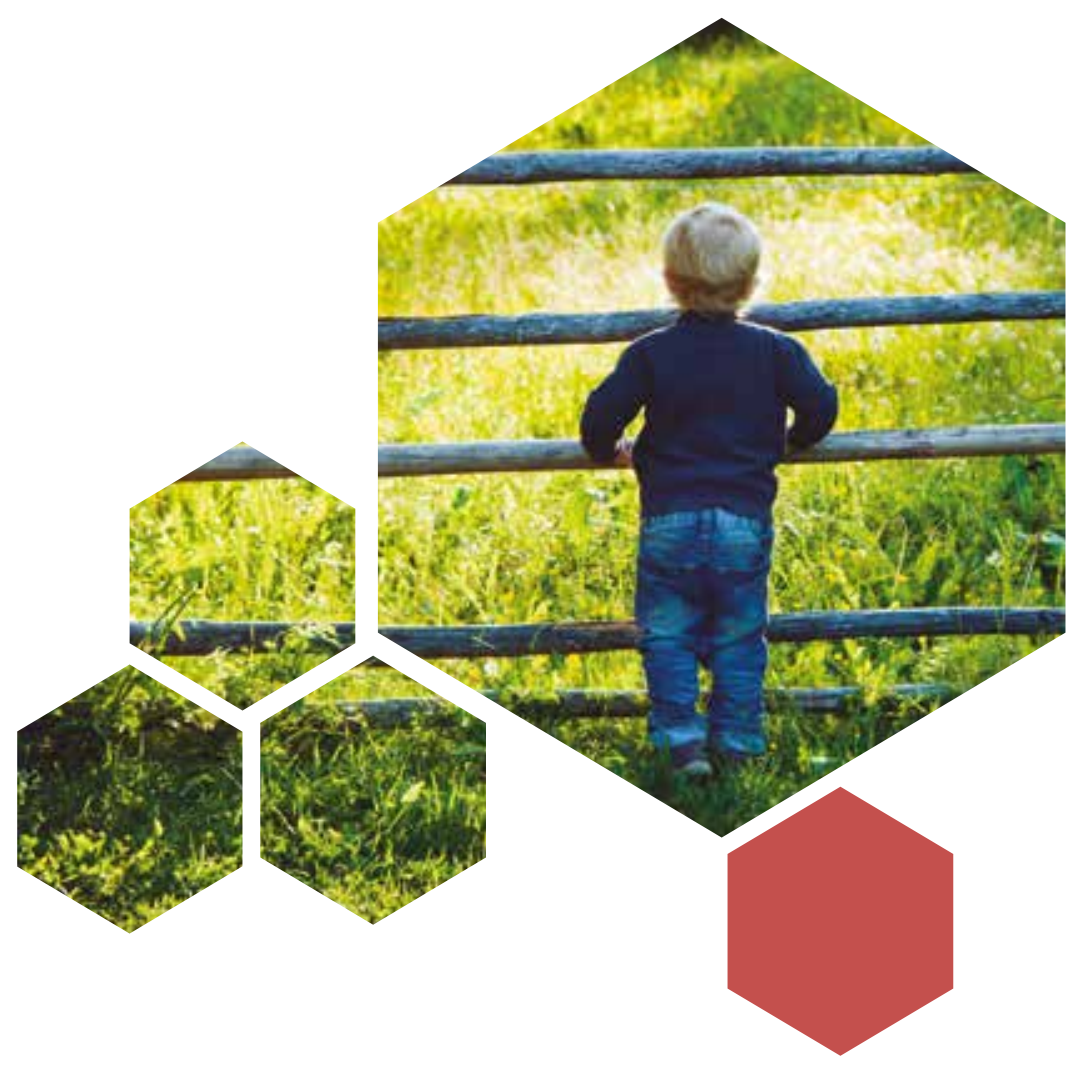




\section{norden}

Nordic Council of Ministers

Ved Stranden 18

DK-1061 Copenhagen K

www.norden.org

\section{The Nordic Region - Leading in Green Growth}

Status report for the Nordic Prime Ministers Summer Meeting 2015

In November 2011, the Nordic Prime Ministers commissioned the Nordic Council of Ministers to launch a cross-sectoral initiative for green growth on the basis of eight recommendations in selected areas. The commission was based on the report, The Nordic Region - Leading in Green Growth, prepared by a Nordic working group.

The initiative was based on the notion that the Nordic countries, by working together, can far better utilise their position to help increase energy efficiency, develop sustainable energy, innovation and research initiatives, and raise the targets in the environmental and climate area.

The Councils of Ministers have implemented the eight recommendations of the working group through project activities that run until 2016. This status report presents the most important results of the projects.

More information about the initiative is available on the Nordic Council of Ministers' website, www.norden.org/greengrowth. 